\title{
Culture as Philosophy of the First Order Activity
}

\author{
Celestine Chukwuemeka Mbaegbu \\ Department of Philosophy, Nnamdi Azikiwe University, Awka, Nigeria \\ Email: coopermbaegbu@yahoo.com
}

Received 13 September 2014; revised 6 October 2014; accepted 18 October 2014

Copyright (C) 2014 by author and Scientific Research Publishing Inc.

This work is licensed under the Creative Commons Attribution International License (CC BY). http://creativecommons.org/licenses/by/4.0/

c) (i) Open Access

\begin{abstract}
Any philosophy is closely tied to and truly inseparable from culture. This paper specifically examines the ontological status of any culture. In its full stretch, it focuses on whether or not there is any "philosophy" in a people's culture and if in the affirmative, what type of philosophy it is, and how it relates to scientific or strictly academic philosophy in vogue of nearly all the academic institutions of higher learning in Africa and in many other foreign nations as well. The method employed in this article is hermeneutics, a method used to mid-wife philosophy from culture since it frames the dialectics between philosophy and non philosophy. The writer concludes that culture is philosophy of some sort or philosophy of the first order activity; it provides the professional philosophers the data base on which to transcend into pure, critical philosophy. The thin line between the two senses of philosophy, namely, philosophy in the strict sense and in the loose sense is thereby clarified, linked and joined in a mutual relationship of bedrock provision.
\end{abstract}

\section{Keywords}

Socialization, Philosophy, Civilization and Culture

\section{Introduction}

The chief sense in which meaning can be made of this paper is the sense in which culture is a raw material for philosophical activity. And, we think it is in this sense that all others are united. This paper therefore advocates that: culture forms the basis, and is a raw material for philosophical reflection; that culture, though arising from some form of ordered thought process is not philosophy in the sense that the handling of items or money which can be enumerated does not make the activity of handling them mathematically. Thus philosophy must be understood as an academic activity involving rigorous and profound search for the truth of reality. Consequently, with its hermeneutical tool, philosophy aims, among others, at the rationalization of cultures. It is equally aimed 
at the provision of adequate basis for the acceptance or rejection of certain elements of culture in a world that has been so culturally torn apart. At this juncture, the power of philosophy becomes so pertinent in solving the present clash of global cultures that are prevalent in our volatile and precarious world.

\section{Definition of Terms}

It is thus instructive to begin with an attempt to clarify and define our principal terms of reference so as to acquaint ourselves with emergent meanings from beclouded notions. For as Mason (1985: 105) rightly remarks that:

Principles are seriously misleading if they are not correctly rooted in a proper understanding of the concepts from which they emanate. The search for the meaning of concepts and the establishment of principles are par excellence philosophic tasks. Although the clarifications of concepts and the elucidation of principles will not have themselves solve concrete issues, nevertheless, without the conceptual clarification of the philosopher, the issues are never adequately resolved.

Most times, the clarification of concepts solves problems where the problem lies with meaning or linguistic clarification. Again, we shall examine the relationship between philosophy and the historical attempts of philosophy at the justification of culture. An examination of the notion of culture as philosophy in African philosophy will then follow, so as to bring out the thrust of our discourse; that culture exists only at the first level of the order of philosophical activity.

\section{Philosophy: A Functional Definition}

The question of what is philosophy is a recurring one. What is now important, however, is to take a firm stand on its answer. The definition of philosophy has become so controversial that philosophers have allowed themselves to be immersed in the same murky waters as the social scientists' that are unable to render unanimous and clear-cut definitions of most concepts in their disciplines.

Philosophers often offer piecemeal definition of their subject. People confine this definition within the branch of philosophy in which they are tutored, the age in which they live, or their moral or cultural bias. Others, in undue haste to answer the question or for lack of knowledge define philosophy merely by its tools or method of inquiry often highlighting the difficulties inherent in both. For example, Wittgenstein and his school of thought emphasized logical clarification of language as a mere description of philosophical method than a definition. Another example is the criticism of criticisms of John Dewey which merely describes the critical nature and argumentative tool of philosophy. Consequently it cannot serve as a penetrative and elucidating definition. Henry Sidgwick (1902: 105) raises this problem of definition in a loud tone. He frames it: "this lack of consensus of experts as to the method and main conclusions of philosophy is I fear, strong evidence that study of it is stillafter so many centuries-in a rudimentary condition as compared with the more special studies of the branches of systematized knowledge that we call sciences”. However, Russell (1959: 93-94) has assured us of the inherent value of philosophy by contending that:

Philosophy is to be studied not for the sake of any definite answers to its questions, since no answer can, as a rule, be known to be true, but for the sake of the questions themselves since these questions enrich our intellectual imagination, enlarge our conception of what is possible and diminishes dogmatic assurances which closes the mind against speculation; but above all because through the greatness of the universe which philosophy contemplates, the mind is also rendered great and becomes capable of that union with the universe which constitutes its highest good.

It is thus clear that inconclusiveness of philosophical answers and similar principles are operational rules that enhance the entrance and reception of possibly true or better alternative modes of thought as found even in scientific modification of theories. Little wonder Sidgwick consistently in all his writings insistently reiterates the hope which philosophy gives of the answer to those things to which appeal to reason is impossible and, repels us from those things of which our acceptance is apt to slide us into dogma. This idea flows mostly from his History of Western Philosophy. The following citations suffice to convey his idea of philosophy as contained in this book.

Lack of proper understanding of these characteristics and nature of philosophy has even led some scholars to contend that philosophy is at best a process and activity and not a definite body or organized form of knowledge. In view of the above notions, Sidgwick (1902: 105) proffers that: 
It is evident that this acquaintance with arguments is not the kind of knowledge at which philosophy aims, although it may be mistakenly all the knowledge for which a consensus of experts can be claimed at present. So long as this is so, the notion of philosophy being a pursuit rather than a system of knowledge will maintain itself, as it has maintained itself throughout two thousand years in which dogmatic systems have succeeded each other:

All these constitute the factors contributing to the difficulty in comprehending the real nature and substance of philosophy. Consequently scholars are often scared of defining philosophy given the pre-supposition of awaiting criticism on the one hand and the difficulty of articulation of the composite nature of the generality of philosophical problems on the other hand. This might be what led Sidney Hook to decline offering a formal definition of philosophy; and G. E. Moore into pointing at the works in the library referring to their mastery as acquaintance with philosophy.

Some are even so daunted as to deny the possibility of a definition or meaning of philosophy. To be precise, it is amazing that a master of the rank of Bertrand Russell could join the train of philosophers professing this ambiguity. Russell (1961: 455) states that: "the word 'philosophy' is one of which the meaning is by no means fixed. Like the word 'religion' it has one sense when used to describe certain features of historical cultures, and another when used to denote a study or an attitude of mind which is considered desirable in the present day".

The singular reason that philosophy could be applied to the sense in which it is used to describe certain cultural features, and to another in which it is a study of the mind renders its meaning unfixed and this for my part, is simply perplexing. Where philosophy is the study of everything, I have found no contradiction in the rational shift of attention from the study of historical cultures to that of the attitude of the mind, or the result in the same which it produces. Plato had held that knowledge is virtue. Whether this position is true or not, it affords us the knowledge that a certain sublime attitude is expected to follow the study of philosophy, and education generally. This is the normative and attitudinal objective of education and falls under the province of philosophy which we call Ethics; the science which studies human behaviour and judges it to be right or wrong in some similar way. The merit of Russell's statement above is that it portrays the scope of philosophy as also encompassing the study of culture.

In addition Alston and Brant (1974: 1) have denied not only the possibility of a fixed meaning of philosophy, but also of an exact one as may be found in other disciplines. According to them, "philosophy cannot be given the straight forward sort of definition that is possible for some logos compounded words like Sociology which can be etymologically defined as the study of society or institutions, or Zoology as the study of the taming of animals". As if unaware of the issuing implication, this statement was succeeded by the following paradox:

What is distinctive of philosophy is, rather, the question it raises. The questions are not all of one kind, although they have a kind of logical unity in the sense that very often we cannot arrive at an answer to one of them without also answering several others... We may define philosophy in terms of its questions, as follows: philosophy is an attempt to arrive at reasoned answers to important questions, that fall outside the scope of any particular science, either because they are normative, or especially general, or more fundamental than the questions the sciences raise, or because they are about the universe as a whole.

Rather than proceed courageously to offer a definition in accordance with the philosophical questions which, they admitted was the guide to a comprehensive definition, they succumbed to the fear of the abstract nature of these questions and the tossing wave of the wideness of the subject matter of philosophy and lost focus. The fact that some philosophical questions fall outside the scope of particular sciences is not delimitation to meaning. Meaning should be framed to encompass all that the denominator seeks to enumerate.

The question has bred more confusion than it tries to solve in such a manner that many now give more time to the question and the result is rise in endless interpretation and reinterpretation other than solutions. Others contend with sheer expression of the worry alone, at most gropingly clinging to etymology. We are thus constrained to seek the remote and fundamental cause of this problem. Unless we get to the root of the problems otherwise, they may never be adequately solved. John Shand (1993: 2) is convinced that the problem emanates from the study of the new distinct disciplines, formerly, under the province of philosophy. He then feels that the "definition of philosophy is impossible as it literally meant everything”. All over Russell's writings; it appears that the difficulty of defining philosophy arises from the multiplicity of the subject matter of inquiry. This points to the dangers that Philosophy from the historical point of view consists of two parts that are inharmoniously blended. On the one hand it is a theory which addresses the nature and meaning of the universe. On the other hand it becomes an ethical or political theory as to the best way of living. The failure to separate these two with sufficient 
clarity has been the source of much confused thinking. When a philosopher assumes in advance of enquiry that certain beliefs are true, such a philosopher is guilty of some kind of treachery. That philosopher has already placed such government censorship upon himself.

Elsewhere, he (Shand) corroborates this stand by arguing that Philosophy is distinguished from science by the fact that an essential part of its purpose is to tell men how to live. Its cosmological and ethical theories are closely interconnected. Sometimes ethical motives influence the philosophers views as to the nature of the universe and in some cases, his views as to the nature of the universe may lead him to ethical conclusions.

He goes ahead to show why philosophy is obscure, cannot record significant progress and results in a queer altitude of mind of its followers. Consequently the philosopher's temperament is rare because it has to combine two somewhat conflicting characteristics which on the one hand is a desire to make some general propositions about the universe and human life. On the other hand a desire to tell men how to live. The more profound the philosopher, the more intricate his fallacies must be in order to produce in him, the desired state of intellectual acquiescence. That is why philosophy is indeed obscure.

From the foregoing, it is undue repetition to emphasize that he (Russell) sees the delineation of disciplinary borders, the spilling over of ethical positions into physical (natural) theories as the bane of philosophy.

We add that the culmination of these views namely: the critical nature of philosophy, the wideness of its subject matter and its many branches, the operational method of inconclusiveness of answers of philosophical questions, and its diverse tools of inquiry: the dialectical, hermeneutical, transcendental phenomenological, inductive and deductive methods blur a clear view of what philosophy is thereby making it susceptible to the difficulty of clear or easy understanding and a composite definition. Fears expressed by previous authors are now also a source of further fear. Fear begets fear and a reproduction of loss of courage pervades.

We submit that while the factors outlined above can hinder definition, they cannot becloud meaning in a most diligent consideration. In the words of Sidgwick (1902: 105): "as philosophers we aim at knowledge of the whole, and therefore at knowledge of the underlying reality". An acceptable definition must reflect the generality of the subject-matter which philosophy contemplates, or the wholeness of the universe which it seeks to comprehend. Here, the bravery of the ancient philosophers deserves commendation. The most acceptable definition of philosophy survives in the writings of the ancients and medieval thinkers. Cicero in his De Officiis says philosophy is rerum humanarum et divinarum causarumquae scientia (the science of things, human and divine and of their causes). Here the philosopher failed to incorporate the notion of purpose in his definition for philosophy also seeks to understand the ultimate purpose of things. It is the same with that of the school men like St. Augustine and St. Thomas Aquinas. They defined philosophy asscientia rerum per ultimas causas (knowledge of things through their ultimate causes). Like the definition given by Cicero, they also failed to add purpose to their work.

The contemporary period has also witnessed hopeful attempts at a holistic definition. According to Okolo (1992: 10):

Philosophy in its academic or professional meaning is a critical enterprise, something dynamic, a quest, a search, indeed one would even define it as a spirit of evaluative exploration or inquiry into all areas of human experience, of the world in which we live, of man himself and his place in the universe...in its widest range so to speak, philosophy tries to give a coherent and systematic account of the multi-faceted universe of being and knowledge; of what is and how man knows it. In short, philosophy carries out a critique of daily experience in quest of truth of all existence as, is rationally possible for man.

Suffice it to say that a discipline is defined by what it studies, and as Alston and Brandt rightly argued, it is also defined by the nature of questions it raises. For instance, in view of the fact that Biology raises questions about the physiological composition of living things, Biology is, therefore defined as the study of the physiology of living things. Its definition thus emanates from its etymology: Bio + logos, meaning life and study or science respectively. Biology is therefore the study or science of life. This is unlike the etymology of philosophy which does not define it. Its definition is not rooted in its etymology. This is contrary to a popular notion held even among philosophers. Specifically, the word philosophy springs from two Greek words: Philos and Sophia meaning love of wisdom. Although, there is a sense indeed, in which the study of the whole universe means a quest for wisdom. But this notion must be examined in relation to periodic and circumstantial background in which it was founded. Literally, the etymology of philosophy describes the inspirational drive for the study of philosophy but not what it studies nor its end. Thus, we see motivation overriding content.

We suspect that since all disciplines were at the time of the origination of philosophy studied under it, such 
that it is the only form of education at the time, there could not be any other name to qualify the wisdom that attends education which only the study of philosophy constitutes than this love of wisdom. For the study of it was and is still revered as pursuit of great wisdom. This name may have emerged as repute for those who gain the knowledge that comes through being educated by it.

As remarked by Shandy (1993: 2) the etymology of philosophy somewhat became a source of confusion as to a proper articulation of the meaning and definition of philosophy. The point is that often times the etymology of a branch of learning may differ slightly from its subject-matter. The constant element is the subject-matter and not etymology. As a matter of fact, the etymology of philosophy is not the definition of philosophy.

Philosophy raises questions about the whole universe, the nature of life and existence. It is in this light that Azad (1952: 21) posits that "philosophy is an inquiry into the nature of life and existence". As Cambridge Dictionary of philosophy tells us, nature is the type or main characteristics of something, the force that is responsible for physical life, therefore our statement that philosophy is the study of the meaning, nature, and essence of life, of all there is includes man's experiences, in their diverse and unified forms and these amounts to a composite definition of philosophy. Heidegger sums it up by saying that philosophy is man's search for the meaning of reality.

\section{Culture and Its Tenets}

Sociologists and anthropologists define culture by the generality of what characterize the life of a people in a society forming the basis of their social existence. The word culture emanates from the Latin word, cotere which means to till the ground; to cultivate. According to Lapiere (1973: 27) culture is defined as "the heritage of wisdom, or more properly, the totality of inventions and discoveries, that is added to and passed on by each, successive generation”. He enumerates the elements and shared-values that make up a total culture as against what they refer to as basic culture.

Considered abstractly, culture consists of skills whereby tools are made and used. It equally comprises patterns of human relationship and symbolic devices, such as words, concepts, and appropriate motivations, sentiments, values, and other human attributes which result in the use of such skills and patterns. I view of these; Lapiere sees culture as a system in that each of its multitudinous elements has a more or less functional interdependence with all the others.

Schaefer and Lamm (1997: 1) gave an abridged definition of culture when they stated that "Culture includes the ideas, values, customs and artefacts of groups of people”.

Presently, the word culture connotes socialization. Nowadays, sociologists emphasize the learned attributes of culture; its generational transmission and the tendency to expand. Lapiere (1997: 30) reminds us that "the most of what any human being learns as he grows from an infant to an adult is culturally indicated". He thus maintains that it is in those processes in toto (in all) designated socialization, rather than in the fact of culture, that a partial explanation for the persistence and continuity of social actions has been found.

\section{The Resultant Effects of Culture on the Society}

There is a sense in which culture is taken to be, but not confused with society. As a matter of fact, one cannot think of culture without taking cognizance of the society. This is because every culture is situated in a society. Often times, due to the large border of the society, more than one culture may be found in it. In this sense, the term culture has been loosely used to designate societies, probably because the borders between inherent cultures are indistinct; perhaps, because of the quest for a common identity spurred by the attending benefits.

Culture is a source of identity in that it is a means being a means of the expression of political, economical, religious and geographical identity. As Ogugua (2004: 61) argues, culture "gives identity to different human groups". As a result, it is common to hear people use the terms culture and society interchangeably. Moreso, the phrase "cultural identity" is not a recent one. This is the sense to which Ogugua refers by writing that "we have one human culture, for it is that which distinguishes man from animals". In the words of Alfred Kohn, it refers to the human environment of humans. It is in this sense that we can abstractly enlarge culture to become global (universal) culture. It is also on this broad sense that we can, though not very appropriately, speak of race as culture. Thus culture can, and is being used by writers and actors to designate racial identity. From the foregoing, we can say that culture is an ambiguous term with a wide range of applications.

Suffice it to say that, every society strives to protect and preserve its culture. To this end, culture wears a po- 
litical garb. It is the basis of national pride. Culture becomes the bedrock of nationalist spirit often giving rise to pride, envy, hostility or hospitality, as the case may be, and in relation to other cultures or societies. Ogugua (2004: 61) attests to this when he argues that: "at times it is charged with emotional overtones which evoke great sense of sensitivity and hostility. For instance, the German Romantic School qualified it as the spiritual essence of that period and the soul of civilization. It has the meaning cultivation of the mind". On this note lies, our contention that culture is altitudinal and behaviour-oriented.

It is common place to hear of the dynamic nature of culture which refers to the efforts made by every society to socialize and ensure generational transmission of its cultural contents. These aim at reflecting changes and advances in modes of thought, arts, science and technology, behaviour and perception. It is pertinent to say that the gradual or rapid modification of cultures and civilization gives rise to the real or imagined feeling of cultural superiority or inferiority and the present tide of global cultural crisis.

\section{A Historical Overview of Philosophy and Culture}

In our examination of the meaning of culture, its political trait was emphasized. It was indicated that, in addition to breeding a cultural nationalist, culture also produces in its members, an attitude towards its preservation, protection and expansion and these emanate from the attendant nationalist spirit, which is expressed through envy, hostility or hospitality towards other cultures.

We equally likened the term culture to society. In the past the term culture was said to have shared some distinctive features with tribal groups. Ethnologists use it to differentiate the marked characteristics of different ethnic groups. From ethnic groups, it was extended to race, for there is a sense indeed in which culture is used to mark the shared characteristics of a race. It is at this level of advanced application of culture that it transforms into civilization. Little wonder some scholars like Ogugua and Oguejio for call it the soul of civilization; the spiritual essence according to the Germans.

Civilization refers to human society with its highly developed social organizations. It also refers to the culture and the way of life of a society or country at a particular period in time. Civilization is simply the word used to qualify the cultural achievements of a particular society, ethnic or tribal group and race, as the case may be. Civilization is the celebration of cultural achievements. The expansionist character of this celebration has led to the reign of the Egyptian civilization whereas the spiritual essence has led to the advancement of cultures. These explain the German Holocaust and the cruel reign of the Roman Empire. All these have their root in cultural advancement in civilization.

Literally, philosophy has tried giving rationality, however unreasonable, to the logic of the expansionist, hostile nature of these civilizations. For want of space we can only take Hegel's Philosophy of History, which is but adoration of European race and of German superiority. For example, he denied rationality to the Africans. Scholars, especially of African descent, have disputed him and his school by referring to the claim of racial superiority as a myth. Briefly, these peel out the relationship between philosophy and culture.

\section{The Interrelatedness of Philosophy and Culture}

Now, it must be admitted that philosophy and culture are two related concepts separated by a layer so thin that this thinness has been a source of much confused thinking. Such relationship has led to a tendency to equate philosophy with culture. This trend is particularly pervasive in contemporary African philosophy. The blame does not only lie so much on African philosophers but also on the methodology set forth by philosophy's founding fathers.

To begin with, the origin of philosophy is located in wonder as Aristotle (982b: 10) would want us to believe that "It is through wonder that men now begin and originally began to philosophize". In his book, The Republic Plato in Bodunrin (1985: 1) records that "there is no other beginning of philosophy than this wonder". Heidegger attests more insistently that the pathos of astonishment thus does not simply stand at the beginning of philosophy as, for example, the washing of his hands precedes the surgeon's operation. Astonishment carries and pervades philosophy.

This wonder by which philosophy began was about the universe, the organic unity and complementarities of its disparate parts and the concrete realities of daily experience. This daily experience results in the interaction of man with nature and of human social existence. Human social existence is rooted in culture; culture dictates the behaviour and life pattern of individual members of society to a great extent. Thus, the first attention of phi- 
losophy on nature ran concurrently with its attention on the hurly-burly of social existence; on culture.

We recall vividly the Socratic history. Socrates preached against the bad morals of the people of his time-a professional philosophical attitude that earned him his own death. In fact, the very two branches of philosophy: Ethics and Social and Political Philosophy are the two main branches that are associated with cultural philosophy. Since both areas seek to control human behaviour, and behaviour is the main content, focus and goal of culture, then philosophical acquaintance with them is invariably, philosophical acquaintance with culture. Moreover, philosophy reflects on man and man is at the centre of culture, for without man there can be no culture. Writing on the same issue, Omoregbe in Bodunrin (1985: 2) contends vehemently and correctly too that:

Philosophizing can also start from the human person. Indeed man has within himself a richer source of philosophy than the physical universe. For the marvels and the complexities of the human person far exceed those of the physical universe. The brevity of human life, the vicissitudes of life, man's superiority over the rest of nature which he controls and dominates, his power and weaknesses, his joys sorrows, successes and failures, his finitude, his experience of suffering, misery, disease, death and decay, man's greatness and misery etc; have led to deep reflection and philosophizing all over the world.

If one reads Omoregbe further down, it would be gleaned, as in this quotation, that not only did culture gave rise to philosophy by providing the base or raw materials for any philosophic enterprise, but it also paved way for the relationship that we seek to establish. Culture is also described as the menu containing the most essential, ingredients upon which philosophy feeds and thrives. Okere (1983: 14) very insistence in his famous work in show casing African philosophy as an essential hermeneutical activity on African culture was even more elaborate. He reasons:

Philosophy is an effort to understand or comprehend reality as a whole, an effort to discover its meaning and if, as we have just learned from the analysis of hermeneutics, philosophy is an interpretation of life and eventually of culture and is understood as the object of life...philosophy is really a product from raw materials. It is a forging out of thought from the materials of culture. It is an act of intellectual creation where the new creation is a meaning born from the melting of one's total experience.

This analysis is considered significant in so far as philosophy began in wonder about the universe and human culture, we ought also to benefit from the fact that philosophy though universal, is situated in culture. Every philosopher who thinks of culture or the universe must, no matter how objective he may sound, be however latent or meagre, under the influence of his culture. This is because culture orientates the behaviour and influences the perception and outlook of the individual. In so doing, there would be found in the man of culture's interpretation of his world, traits of the basic notions of his culture of the world. Moreover, the experiences which motivate or give rise to philosophic activity are peculiar to his culture. Thus, the philosopher's view of the world, at most, does not transcend his culture but rooted in it. That is why most philosophers contend that every philosophy must be reflective of the cultural and moral position of the writer.

We submit that this is the basis of the philosophy of regional ontology. Put simply, it is the basis for the existence of such racial, regional, and cultural philosophies. Today because of the indispensable relationship between culture and philosophy we hear of Asian philosophy, Indian philosophy, African philosophy, and American, Greek, and British philosophies and so on. The same reason gives rise to philosophies of religious sects and schools. The existence of these cultural philosophies is not necessarily because they are a communal thought; rather, because the philosophies of the philosophers are usually characterized by a common outlook influenced by the culture or social environment from which they philosophized

This factor also explains the qualification of the beliefs, ideologies, and principles, actions of certain individuals, institutions or societies as philosophy. It is believed, as though may be the case, that since the individual philosopher of every culture may have something to say in favour of or against their culture as Socrates did and professional philosophy allows, then such cultural practices have either their input based on some philosophy. Moreover, since philosophy is characterized by free thinking which the methodical question we had raised earlier fosters, and since all human behaviour and principles are based on some reasoned process then they are philosophical. Briefly, all these spell out the relationship between philosophy and culture.

\section{The Cultural Question in African Philosophy}

Having seen the relationship between philosophy and culture, we need not bother to situate our example with much strength on any culture. Although no other culture has the existence of their cultural philosophy generated 
much controversy than in African philosophy, we shall examine this briefly. The fact that this controversy raised to a point it assumed the reference: The Great Debate alone is an illustration as well as a justification for a little space in our discussion.

The question as to whether there existed philosophy in Africa prior to European contact and more specifically, the publication of Tempels' Bantu Philosophy generated the cultural question in discourses with particular reference to African philosophy. The main controversy is whether the various norms, values, folklores, wise sayings and ethnic traditions in traditional Africa constitute authentic African philosophy in the strictest sense of the term. This led to the emergence of two opposing camps of philosophers namely, the Ethno-philosophers and Professional philosophers on this issue. While Ethno-philosophers contend that the enumerated cultural elements are sure indices of a reasoned philosophy, Professional philosophers are of the view that philosophy is simply and strictly the product of a specialized thinking activity of an individual on that of a community that is imbued with an essentially academic character and quality.

The remaining schools, the Sage philosophy and Nationalist Ideological Philosophers are sympathetic with either of the two identified major currents. While it may be said that the sage philosophers due to the content of their argument, are supportive of Ethno-philosophers, Nationalist Ideological Philosophers enthrone the academic character of philosophy and therefore are supportive of professional African philosophy. Sage philosophy shares a similar stand with ethno-philosophy, since African philosophy may be found or sieved from the wisdom filled thought of the African sage. While they were busy heating up the debate, National ideological philosophers were conditional by the exigency of their existential circumstances to reel out series of social, political, ethical, metaphysical and epistemological philosophies.

The preceding analysis, lends credence to the relation between philosophy and culture but without much emphasis on the differences. The essence was to allow the source of the confusion which equates philosophy with culture to manifest itself. We succeeded in showing how communal thoughts and individual or institutional principles of behaviour and policies of action commonly referred to as philosophy are philosophy in a loose sense of the term. Now, let us examine this notion more closely.

Culture as we have seen, is the sum total of the assumptions entertained by a group of people. Man, whether a philosopher or not, has a natural inclination to know and this is driven by his rational instinct and power. He thus desires, cherishes and pursues knowledge. This is what Aristotle describes in the introduction to his celebrated Metaphysics as man's natural desires to know. It follows therefore, that all his actions based on some order proceed from a well thought out knowledge. Culture, in this sense, flows from a well thought-out knowledge. Indeed, it is founded on some thought-out reasons and follows an order of procedural thought. That is why culture is dynamic. It changes over time to reflect changes in thought and perception most of which are substituted with an improved knowledge. This shows that, like philosophy which renews itself with the food of constant thought, culture also reproduces itself with the power of constant imaginative thought and reflection. As such, they share this common characteristics in some lesser or greater degree.

But that does not make culture a philosophy. To equate the process leading to a cultural order with philosophy is to deviate from the essential philosophical character of genuine devotion to wisdom, knowledge and the activity of critical reflective and enduring questioning. As we saw, this essential character equips philosophy with the tool with which it thinks deeply upon culture and even upon itself. Ethnographers and professional philosophers alike agree on the point that, philosophy is essentially a reflective activity. Their point of divergence is on the determination of the critical and engaging character of this reflection in Pre-Tempelsian Bantu Philosophy in Africa. Denying Black Africa this reflective activity would not only be denying her rationality or the power of reflective thinking but also meting out injustice to our fore-bears who may have pre-occupied themselves with such thinking and activity that we call philosophy. In order to witness the professional practice and character of this activity, we are automatically invited to the question of the method of its transmission and preservation.

Hountondji (1996: 33) the most audible of the professional philosophical school insistently writes: "By African philosophy, I mean a set of texts, specifically the set of texts written by Africans and dedicated as philosophical by their authors themselves. ... So for us African philosophy is a body of literature whose existence is undeniable”. Kwasi Wiredu (1980) lends credence:

There are bound, of course, to be a number of adventurous minds remarkable in their ability to think critically about the foundations of the folk mentality and make original contributions to the fund of public philosophy. But the lack of writings robs many traditional societies of the richness in depth, rigour and variety which communal dialectic of individual efforts preserved in script can yield. This is not to belittle traditional philoso- 
phy. In any society, developed or developing there is a subtle interaction between the intellectual productions of even the boldest minds and their background of immanent public thought.

The difficulty of preservation of the thought of the pre-modern African thinkers through channels other than writing such as mythologies, formulae of wise-sayings, traditional proverbs, stories and especially religion, made the whole difference since these means do not only insufficiently tell us how and what the logical processes leading to such philosophies were, but also fail to avail us of the authority of the individual thinkers themselves. These would have cleared this air of confusion and convinced us of the prevalence of a lively professional philosophical activity in Africa.

In rejecting this criterion, Omoregbe (1985: 5-6) states that "we must distinguish between philosophy and its mode of transmission and preservation. By far the best way to transmit and preserve them is by writing, in the form of books" contending that philosophical reflections can be preserved and transmitted in a number of ways. This is, undeniably true. But it must be remarked and admitted that the present wake or rebirth of African philosophy is suspiciously separated in time and space from the time of the flourishing of the said African philosophy received in myths and stories from the presumed ancestors famously referred to as pre-modern African thinkers.

The point of it all is that if there was philosophy in pre-modern Africa, such a philosophy must, no matter how faint, survive not only in wise sayings but also in generational transmission or continuity of individual or even communal thinkers as is the case in other native African arts, custom and religion. It is surprising that where such a philosophy is said to have existed, it was so historically disconnected from the trace of the communal or individual thinkers and it relied only on guess work for ascertaining their existence. Moreover, if this existence could be established, there must have survived remnants of the academic study or wisdom centres where they were practiced. Of course, we can lay claim to the Egyptian monasteries and mystery systems as not only evidence of the existence of philosophy, but also the origin of Greek philosophy. Perhaps, the art of philosophizing in Black Africa could not advance beyond family houses and tree shades, or it existed only in Egypt.

We fear that philosophy, if it existed in this form in pre-modern Africa i.e. if it did not transcend culture is not philosophy. Philosophy embedded in culture is non-academic; and non-academic philosophy is not pure but applied philosophy in the same sense that the non-academic organization of human beings into a political order and government is not enriched with the intellectual rigours of the study of politics and, is, neither political science nor political philosophy except perhaps, applied political science.

Sufficient examples have been adduced by scholars to drive home this point. Every man is a philosopher, they argue, in so far as he is endowed with the natural instinct of curiosity and wonder and the faculty of reason. And in so far as his experience spurs him in one way or the other to reflect on the universe and same experiences. Nevertheless, his reasoning does not strictly proceed in the academic order laid down for philosophic investigation save by training and insight. It is in this sense that whatever we think of or do may be called philosophy since it must have been accompanied by some thought process and conceivable reason. This is the sense in which every man is a mathematician, because he engages in activities which involve constant calculation. But every man is not a mathematician in the sense of its academic character of professionals devoted to the pursuit of the origin and solution of the problem of numbers.

\section{Conclusions}

Culture, in the sense in which it is a reasoned order, laying down principles upon which the life of a people may be guided to presumed prosperity is a philosophy. But it is as we have shown philosophy in the loose sense. It is not philosophy in the strict academic sense of the term. Therefore we must clarify and settle this issue of the existence or non-existence of philosophy in traditional Africa. If there was such a thing, we did not know it because of the complexity in transmission of ideas, insights and thoughts. We must emphasize that philosophy, even as Omoregbe and others admitted proceed in three steps culminating into the procedural completion of the three stages; the first step being the wonder that accompanies man's experiential contact with himself and the world around him. This wonder, of course, gives rise to some fundamental questions and this is the second step. The third which is the culmination of philosophical activity now occurs as man begins to reflect on the raised questions in search of answers to them. Thus, philosophy must start from the level of wonder to that of questioning of experiences among which is culture, to the level of supposed answers to them. This is the stage of pure philosophy. If it stops at one stage then it fails to reach the status of philosophy and becomes quasi or semi 
philosophy.

We find evidence to this philosophical process in Ricouer (1969: 14). He speaks of three stages that must accompany the transformation from symbol to thought that is "the phenomenological, the hermeneutical and the reflexive stages" converging with the three stages outlined above, as in other cultures, African culture, wisesayings, stories, myths folklores etc. stop at the first stage of this procedural step of philosophizing. Thus Okere (1983: 14) pointedly concludes:

If this is the type of dialectical relationship there is between philosophy and culture, our thesis is this: that Black Africans, having their own cultures, can have their own proper philosophies by deriving and elaborating them from their own cultures. But it is not enough to have a culture in order to have also a philosophy. Mediation, a passage from culture to philosophy is necessary.

The same contention radiates from his words cited in our discourse on philosophy and culture. Thus considered, culture exists at the first order of philosophical activity. Put differently, culture exists at the first order activity at the level not yet acted upon as to transform it into pure philosophy. Thus culture exists at a level of philosophy not yet ripe in rigour for the status of pure philosophy; it is as good enough material for pure or academic philosophy since in logic we cannot assign to a part what belongs to the whole. Philosophy exists at the third order of philosophical activity and that is its proper ontological status. In conclusion, we must reiterate that philosophic activity begins with culture, by feeding on it as it progresses into the highest order of reflective activity of a reflecting people which is the domain of pure or academic or professional philosophy. It must be admitted that no philosophy begins in a vacuum. It begins and springs from a people's culture making philosophy a reflective activity of a reflecting people within a particular culture.

\section{References}

Alston, W. P., \& Brandt, R. B. (1974). Problems of Philosophy (2nd ed.). Boston: Allyn \& Baton.

Aristotle (nd). Metaphysics.

Azad, A. M. (1952). Introduction to Sarvepalli Radharkrishnan: History of Philosophy Easternand Western (Vol. 2). London: Allen \& Unwin.

Bodunrin, P. O. (1985). Philosophy in Africa: Trends and Perspectives. Ile-Ife: University of Ife.

Hountondji, P. J. (1996). African Philosophy, Myth and Reality. Indianapolis: Indiana University.

Lapiere, R. T. (nd). A Theory of Social Control. New York: Mc Graw Hill.

Mason, T. F. (1985). Towards a Philosophy of Pluralism. In P. O. Bodunrin (Ed.). Philosophy in Africa: Trends and perspectives (pp. 105-127). Ile-Ife: University of Ife.

Ogugua, P. (2004). African Culture and Democracy. Unizik Journal of Arts and Humanities, 5, 55-68.

Okere, T. (1983). African Philosophy A Historico-Hermeneutical Investigation of the Conditions of Its Possibility. Lanham: UPA.

Okolo, B. (1992). Problems of African Philosophy. Enugu: Cecta.

Omoregbe, J. I. (1985). African Philosophy Yesterday and Today. In P. O. Bodunrin (Ed.), Philosophy in Africa: Trends and perspectives (pp. 1-14). Ile Ife: University of Ife.

Plato (nd). The Republic.

Schaefer, R. T., \& Lamm, R. P. (1997). Sociology: A Brief Introduction (2nd ed). New York: McGraw Hill.

Russell, B. (1959). The Problems of Philosophy. New York: University Press.

Russell, B. (1961). Basic Writings of Bertrand Russell. London: Allen Unwin

Ricoeur, P. (1969). Le Conflict des Interpretations. Paris: Du Seuil.

Shand, J. (1993). Philosophy and Philosophers: An Introduction to Western Philosophy. London: UCL.

Sidquick, H. (1902). Philosophy, Its Scope and Relations: An Introductory Course of Lectures. London: Macmillan.

Wiredu, K. (1980). Philosophy and African Culture. New York: University of Cambridge. 
Scientific Research Publishing (SCIRP) is one of the largest Open Access journal publishers. It is currently publishing more than 200 open access, online, peer-reviewed journals covering a wide range of academic disciplines. SCIRP serves the worldwide academic communities and contributes to the progress and application of science with its publication.

Other selected journals from SCIRP are listed as below. Submit your manuscript to us via either submit@scirp.org or Online Submission Portal.
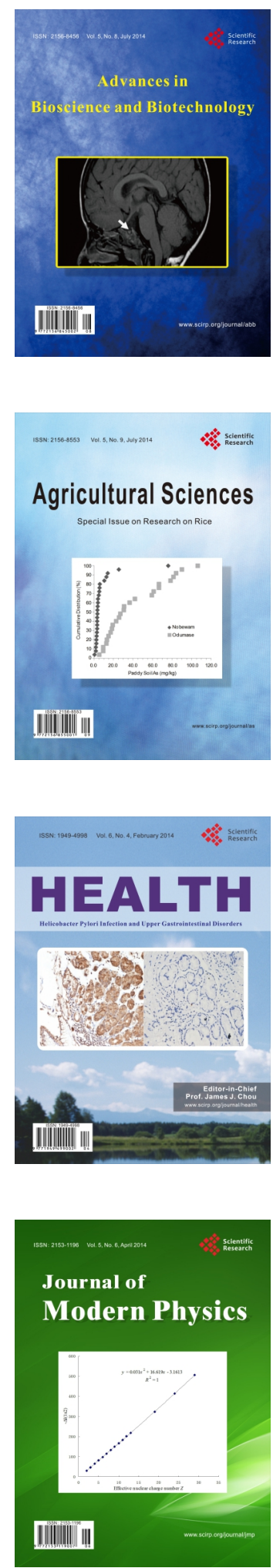
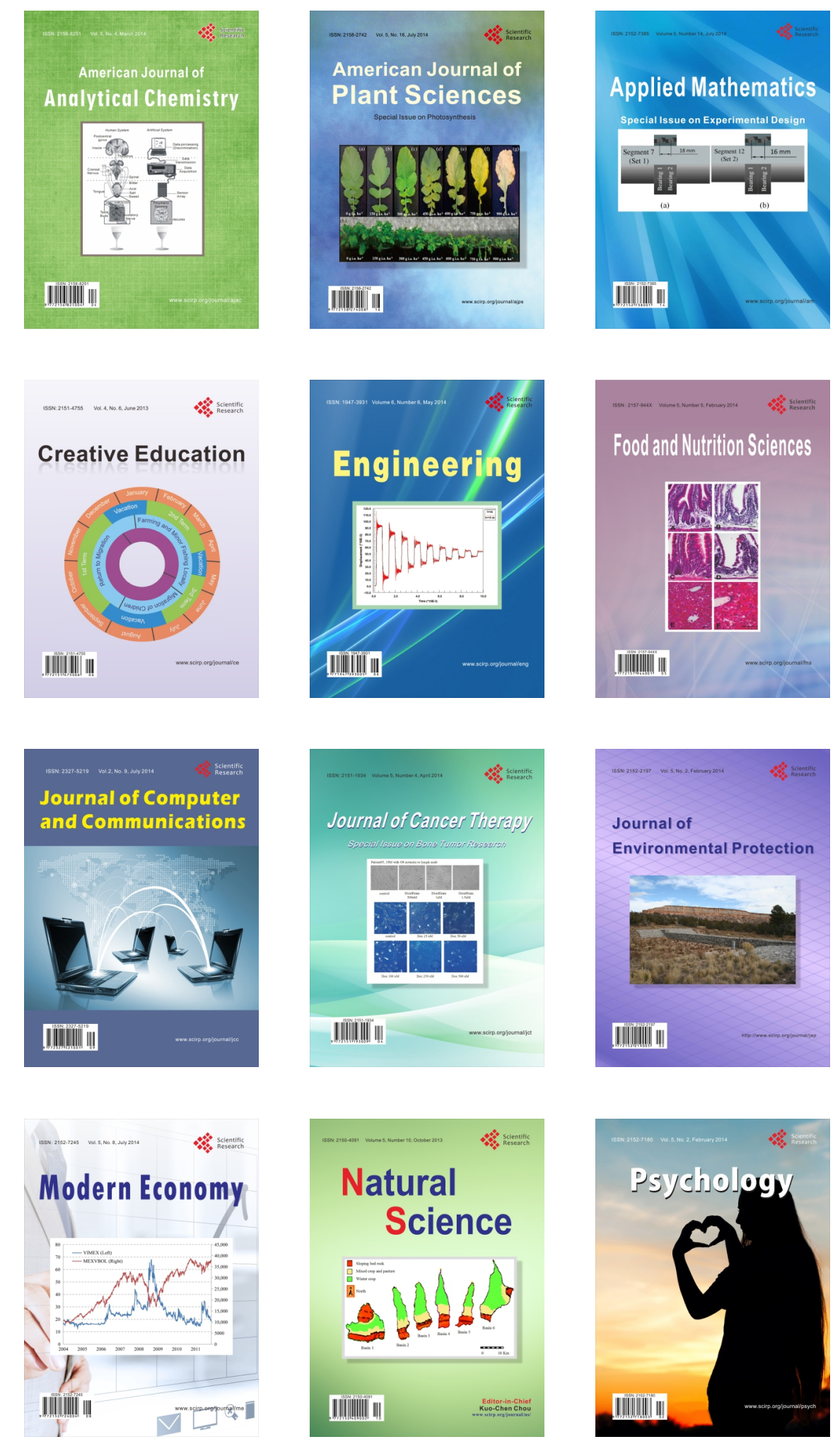